EM JEITO DE POSFÁCIO 


\section{Da suspensão do quotidiano aos dias por vir: convites a pensarmo-nos}

https://doi.org/10.21814/uminho.ed.25.16

\section{Rui Vieira de Castro}

Rui Vieira de Castro (ORCID: 0000-0001-7294-1705) é Professor Catedrático do Instituto de Educação e Reitor da Universidade do Minho. 
1.

Devastação e desolação são palavras que descrevem adequadamente os efeitos, pressentidos ou vividos, da pandemia da COVID-19 nos tecidos social, económico e institucional. A ocupação do espaço público pelo tema - durante meses consecutivos foi tópico dominante na cena comunicacional - dá-nos a dimensão precisa da importância do que se passou e continua a passar. Quando se considera não o que se passou ou vai passando, mas o que se pode passar, a palavra incerteza é a mais comummente mobilizada.

Num contínuo balizado por uma imprevisibilidade ameaçadora e uma esperança de estabilidade se foi desenvolvendo a vida da Universidade do Minho ao longo do primeiro semestre de 2020. Um tempo duro, pelo que implicou de radical alteração das circunstâncias internas e externas à Instituição, um tempo desafiante, de reconfiguração e de reinvenção da própria Universidade, impelida a encontrar novas formas de organização e de ação, um tempo de compromisso, com a contínua reafirmação da missão da Universidade, nas dimensões da educação superior, da investigação científica e da intervenção no contexto social e económico, um tempo de reflexão, condição para a manutenção do rumo, mesmo que restringida pelos imperativos de urgência que a necessidade da ação impunha, um tempo de projeção, ainda que a indefinição e o imprevisto se mantenham como elementos marcantes do nosso contexto.

\section{2.}

O que tem ficado de tudo aquilo que vivemos e vamos vivendo na Universidade? Uma pergunta que, pelo menos do ponto de vista de quem isto escreve, se justifica não apenas pela importância de fixar um tempo e uma experiência, mas também pela identificação que permite de forças e de fragilidades, importantes para compreender o que uma instituição é e projetar o seu futuro.

O ponto de vista condiciona inevitavelmente o relato que, por isso, ficará sempre afetado por marcas de subjetividade, risco incontornável do registo que se adota e se assume. Falo a partir de uma posição específica, a de reitor da Universidade, e não de qualquer outra; foi essa posição que possibilitou a vivência que agora se descreve e 
interroga, através de um olhar em que o diagnóstico é indissociável da ação e da reação. Este será, pois, o ponto de vista de quem conta.

Quanto ao que é contado. O relato é necessariamente esparso - corro o risco aliás de tentar introduzir um adicional de coerência, que confira sistematicidade à ação e à decisão, onde ela nem sempre terá existido, de estabelecer encadeamentos lógicos, onde muitas vezes houve saltos e sobressaltos, efeito das dificuldades em conviver com o imponderável.

Não se pode falar, senão indiretamente, das experiências e das vivências, dos sucessos e dos infortúnios, das alegrias e das frustrações, ao longo dos últimos meses, das cerca de 22500 pessoas que constituem a comunidade da Universidade do Minho. A complexidade da experiência é irredutível. Admito, entretanto, que as circunstâncias externas e as decisões institucionais, nos seus fundamentos e efeitos, acabam ora refletindo aspiraçốes, vontades, interesses, ora modelando modos de fazer e de dizer. Reflexo e modelação corporizam-se em textos e discursos que criam novos estados de coisas; aqueles que correspondem às sucessivas respostas da UMinho à situação de pandemia.

De algum modo, tento desenhar um roteiro das decisóes tomadas, que foram respondendo à variação das circunstâncias e que foram configurando novas orientações e práticas. A escolha dos tópicos requer comentário, que será, também ele assumidamente pessoal, exprimindo uma determinada valoração da experiência, atravessada embora pela vontade de dar centralidade à Universidade.

3.

\subsection{O primeiro impacto: "um intervalo de suspensão da quotidianidade, uma interrupção do ritmo"}

Foi um tempo curto aquele de que a UMinho pôde dispor para enfrentar a crise sanitária. Em 11 de março, a OMS declarou que se encontrava em curso uma pandemia

1 Os títulos desta e das secções subsequentes são citações de Frente ao Contágio, de Paolo Giordano (secçôes 3.1. e 4), e de A pandemia que abalou o mundo, de Slavoj Žižek (secção 3.2), livros publicados em 2020, pela Relógio d’Água. 
devida à propagação de um novo coronavírus. Tinham passado pouco mais de 2 meses depois que a República Popular da China havia comunicado à OMS que um novo vírus se estava a disseminar no país.

Em 26 de fevereiro, na reunião do Conselho de Presidentes das Unidades Orgânicas, pela primeira vez, o coronavírus foi tópico de uma reunião formal de órgãos da Universidade.

No dia 2 de março, o Governo determinou aos empregadores públicos a elaboração de um plano de contingência alinhado com as orientaçôes emanadas pela Direção-Geral da Saúde, no âmbito da prevenção e controlo de infeção por SARS-CoV-2.

No dia seguinte, na Universidade do Minho, um despacho reitoral nomeava a Comissão de Elaboração e Gestão do Plano de Contingência Interno COVID-19 da Universidade do Minho, composta por Paulo Cruz, Pró-Reitor para a Qualidade de Vida nos Campi e Infraestruturas, Carlos Menezes, Administrador da Universidade, António Paisana, Administrador dos Serviços de Ação Social, Rui Oliveira, Presidente da Associação Académica da Universidade do Minho e Alexandre Carvalho, Professor da Escola de Medicina. Tendo como referência as recomendações da Organização Mundial de Saúde e da Direção-Geral da Saúde, era cometida a esta Comissão a elaboração do Plano, estabelecendo-se que as medidas internas de prevenção e controlo da doença seriam aplicadas a todos os membros da comunidade académica e àqueles que, por motivos profissionais ou outros, se deslocassem às instalaçôes da Universidade.

Em reunião do Senado Académico do dia 4 de março, foram apresentadas as linhas gerais do Plano de Contingência, tema ainda então sobrelevado por um outro que vinha ocupando a atenção dos órgãos da Universidade nos últimos meses - o novo regulamento orgânico das unidades de serviços.

A reunião da Equipa Reitoral realizada no dia 6 de março teve como assunto principal a articulação da UMinho com as autarquias de Braga e Guimarães, na perspetiva da adoção de uma estratégia partilhada de desenvolvimento. Com a evolução da COVID-19 em fundo, é, porém, tomada a decisão de suspensão de uma das principais iniciativas de promoção da oferta educativa - a U(niversidade ) de $\mathrm{P}$ (ortas) A(bertas). 
Face às informaçôes que rapidamente se vão acumulando, ao final do dia são tomadas as primeiras decisões de restrição da atividade por efeito da pandemia, considerando-se a posição da Comissão de Elaboração e Gestão do Plano de Contingência Interno COVID-19. Nesta circunstância, deixam de ser autorizadas deslocaçóes em serviço, ao estrangeiro; são revogadas as autorizaçóes para deslocaçóes em serviço que tenham sido previamente autorizadas; é suspensa a organização de eventos que impliquem a presença física de mais de cinquenta participantes, excluindo-se do âmbito desta medida as aulas previstas e programadas; é suspensa a utilização dos terminais de leitura biométrica para controlo de assiduidade, substituídos por controlo e validação de assiduidade realizado pelo superior hierárquico direto do trabalhador na intranet.

No dia 7 de março, após um telefonema que me foi feito pelo Ministro da Ciência, Tecnologia e Ensino Superior, Professor Manuel Heitor, a Ministra da Saúde comunicava, em conferência de imprensa realizada durante a tarde, a decisão de encerramento do "edifício onde funciona o curso de História da Universidade do Minho", por recomendação técnica da autoridade nacional e das autoridades regionais de saúde.

[7 de março - Reunião extraordinária da equipa reitoral². Notas pessoais] Análise da situação criada pela decisão do Governo. Implicações dos fundamentos da decisão de encerramento do edifício do ICS, motivada pela presença do estudante que havia acusado positivo no teste à COVID-19, na atividade desenvolvida em outros espaços do campus de Gualtar, frequentados pelo estudante em causa.

Às 23:00 é publicado um despacho reitoral que, tomando em consideração a confirmação de um caso de COVID-19, a necessidade de a Universidade assumir uma posição que contribuísse ativamente para a prevenção e o controlo da doença, bem como as recomendaçốes da Comissão de Elaboração e Gestão do Plano de Contingência,

2 A equipa reitoral da UMinho era composta pelos Professores Eugénio Ferreira, Laurinda Leite, Manuela Martins e Ricardo Machado, vice-reitores, e Carla Martins, Filipe Vaz, Guilherme Pereira, Manuel João Costa e Paulo Cruz, pró-reitores. 
determinava, para o campus de Gualtar: o encerramento do edifício do Instituto de Ciências Sociais; a suspensão das atividades pedagógicas; o encerramento dos serviços de bibliotecas e das unidades alimentares; a suspensão dos eventos e atividades desportivas; a suspensão da realização de conferências, seminários, cerimónias e eventos de natureza similar. Aos professores, investigadores, trabalhadores técnicos, administrativos e de gestão e estudantes oriundos de países com casos confirmados de COVID-19 era aconselhada a submissão voluntária a um período de quarentena, após a sua chegada ao país. Adicionalmente, recomendava-se que fosse reduzida ao mínimo, pelos membros da comunidade universitária, a utilização das instalações da Universidade, em Gualtar, bem como limitada a realização de conferências, seminários, cerimónias e eventos de natureza similar no campus de Azurém e nos restantes espaços da Universidade; determinava-se a suspensão de todas as deslocações em serviço.

Em escassas horas, a vida da Universidade do Minho ficava radicalmente alterada.

[8 de março - Reunião com delegados de saúde de Braga, responsável da proteção civil e diretor executivo do ACES. Notas pessoais]

Iniciativas a tomar para preparação da Universidade para um eventual agravamento da situação. Orientaçóes a adotar e modos de lidar com casos suspeitos ou confirmados. Critérios médicos e epidemiológicos de identificação de casos suspeitos. Condiçôes de realização da quarentena. Procedimentos a adotar tendentes a assegurar o corte das redes de transmissão: higienização de espaços, uso de equipamentos de proteção individual, formação das pessoas. Importância da razoabilidade e proporcionalidade na ação. Papel das autoridades de saúde e dos hospitais de referência.

$\mathrm{Na}$ sequência desta reunião, em declarações aos meios da comunicação social, reafirmei que as medidas adotadas diziam respeito ao campus de Gualtar, não havendo, naquele momento, razões para as alargar a outros espaços da Universidade. 
[8 de março - Reunião com equipa reitoral, administradores da Universidade e dos SASUM e responsáveis das unidades de serviços. Notas pessoais]

Necessidade de cuidados adicionais relativamente aos niveis de segurança dos sistemas de informaçôes e comunicaçôes da Universidade, com as ligaçôes por VPN a triplicar. A situação dos estudantes estrangeiros e de mobilidade, em particular a situação dos estudantes em mobilidade em Itália. Importância dos suportes tecnológicos e dos procedimentos administrativos para responder à passagem dos cursos para ensino a distância. A prestação de serviços aos utentes face ao cancelamento dos serviços de atendimento presencial è̀ opção pelo atendimento a distância.

Os serviços de ação social colocam problemas particulares, sobretudo decorrentes da necessidade da existência de algumas dezenas de estudantes em quarentena.

[8 de março - Reunião com a administração dos Serviços de Ação Social. Notas pessoais]

Caraterização da situação nas residências de estudantes. Prestação de serviços de alimentação e apoios de saúde aos estudantes e reforço da limpeza nas residências. Balanço da situação dos trabalhadores dos Serviços pertencentes a grupos de risco mais expostos ao contacto com os estudantes.

O despacho reitoral no 24/2020, publicado no dia 8 de março, cerca das 21:00, estabelecia um conjunto adicional de medidas de emergência. Entre elas avultava o encerramento de todas as áreas de atendimento presencial a utentes nas unidades orgânicas e nas unidades de serviços da Universidade e dos Serviços de Ação Social, o encerramento dos complexos pedagógicos do campus de Gualtar e a adoção de novas formas de trabalho, designadamente teletrabalho, nas unidades de serviços que funcionavam naqueles complexos. Aconselhava-se também os estudantes instalados na Residência de Santa Tecla e na Residência Carlos Lloyd Braga, com possibilidade de 
regressar temporariamente ao seu domicílio, a fazê-lo, minimizando os contatos interpessoais e respeitando as recomendações da Direção Geral de Saúde. Recomendava-se um período voluntário de quarentena aos estudantes que, encontrando-se naquelas residências, tivessem tido contactos de risco; a todos os estudantes que se encontravam nestas circunstâncias eram asseguradas as condições necessárias, designadamente alimentação, cuidados de saúde, higiene, etc.

No dia seguinte, a questão principal que se colocava era a da retoma das atividades letivas, dado que as condiçóes em que havia sido determinada a suspensão da atividade presencial não tinham permitido planear uma alternativa. Como lidar com esta questão crítica, de modo a assegurar o essencial da atividade da Instituição?

[9 de março - Reunião com a equipa reitoral (Educação). Notas pessoais] Identificação das funcionalidades disponiveis para suporte à atividade pedagógica. As potencialidades da BlackBoard (comunicação unidirecional e sincrona; fórum). Características do serviço Colibri. Carência de infraestruturas de suporte ao ensino. Limitaçôes da capacidade das ferramentas disponiveis.

Começou de imediato a desenhar-se uma resposta, no próprio dia 9 de março, depois de dúvidas, expressas aliás na conferência de imprensa do dia 8 de março, sobre a possibilidade de uma resposta imediata e efetiva da UMinho às novas circunstâncias. O uso massivo da plataforma institucional de apoio ao ensino, que permitia interaçôes síncronas e assíncronas entre professores e estudantes, ganhou força, reconhecidas as dificuldades decorrentes da ausência de infraestruturas específicas de ensino a distância capazes de permitir fazer face às necessidades de mais de 3000 unidades curriculares. Equacionou-se, então, uma opção que se veio a revelar muito produtiva - a do uso conjunto das possibilidades da plataforma Colibri-Zoom e da plataforma institucional de apoio ao ensino; foi também o momento em que se começou a assumir como essencial uma aposta forte na formação dos docentes e no envolvimento dos estudantes na reconfiguração dos processos de ensino e aprendizagem. 
Ao longo do dia 9 aumentam os pedidos, com origem em diferentes setores da comunidade, para a extensão das medidas de restrição adotadas no campus de Gualtar (Braga) ao campus de Azurém (Guimarães).

[9 de março - Reunião com representantes dos trabalhadores técnicos, administrativos e de gestão. Notas pessoais]

Apresentação do histórico de factos registados, das respostas institucionais e das perspetivas futuras. Apresentação do Plano de Contingência (PRT PCruz). Preocupações expressas pelos trabalhadores: importância de ações preventivas e não apenas reativas; dúvidas sobre a eficácia de medidas limitadas a um campus, dada a porosidade da Instituição; preocupação com um tratamento diferenciado dos trabalhadores técnicos, administrativos e de gestão, mais "expostos", face a outros, mais colocados em "recato". Preocupação com os trabalhadores portadores de doenças de risco.

Nesta reunião com os representantes dos trabalhadores verifica-se serem dominantes as posiçôes em favor da extensão a Azurém das medidas adotadas para Gualtar, com argumentos fortes como a grande mobilidade de estudantes, docentes e trabalhadores entre os dois campi, a indesejabilidade do tratamento diferenciado das duas comunidades e particularmente dos trabalhadores técnicos, administrativos e de gestão, a situação, difícil, dos doentes de risco, e as questôes relativas ao teletrabalho.

A este propósito, afirmei a necessidade de a Universidade promover ações técnica e cientificamente informadas, recordei a responsabilidade social de todos com o projeto da Universidade, a importância de suportar as decisões nas posiçóes das autoridades de saúde, os significados de uma situação de crise e a recusa da existência de um qualquer tratamento discriminatório, bem como a valorização do papel dos representantes dos trabalhadores.

Num encontro com jornalistas que teve lugar no dia 9 de março, foi assunto principal a situação dos 87 estudantes em quarentena, a quem a Universidade tinha passado a disponibilizar serviços de apoio. Foi reafirmada a intenção, face aos elementos 
então disponíveis, de não generalizar ao campus de Azurém a suspensão da atividade letiva presencial, referindo-se, no entanto, que a situação estava a ser acompanhada muito de perto, estando identificada a existência de um quadro de "grande perturbação” na Instituição. Foi sinalizado o facto de, naquele momento, os responsáveis pelas várias escolas e institutos da Universidade estarem já a “ensaiar” dispositivos alternativos para que o contacto entre professores e alunos pudesse ser mantido, de forma a minorar os efeitos negativos das medidas tomadas. Rui Oliveira, Presidente da Associação Académica da UMinho, também presente no encontro com a comunicação social, deu conta da sua "preocupação" com o que estava a acontecer, indicando que o principal "receio" dos estudantes eram as fontes de contágio; informou, ainda, que a Associação Académica se encontrava a rever todas as suas atividades que podiam ter 'risco' acrescido e manifestou a intenção de apoiar os estudantes 'em quarentena..”

No dia 9, as unidades orgânicas começam a reprogramar as suas atividades. A atividade de investigação mantém-se. Começam a ser exploradas as possibilidades de manutenção da atividade de ensino, com recurso a tecnologias de streaming ou a sistemas de gravação. O Centro Clínico Académico passa a limitar a sua atividade a doentes internados.

[9 de março, noite - Reunião extraordinária da equipa reitoral. Notas pessoais]

Análise de todos as informaçôes disponiveis e avaliação das opçôes. Contactos com a delegação de saúde e o presidente da Câmara de Guimarães. Decisão de suspensão das atividades letivas presenciais na Universidade.

Na madrugada do dia 10 de março, é publicado o despacho reitoral no 25/2020, que determina, para toda a Universidade: a suspensão das atividades letivas presenciais; o encerramento dos serviços de bibliotecas e das unidades alimentares; a suspensão dos eventos e atividades desportivas; a suspensão de reuniões de júris de concursos e de provas académicas; a realização de conferências, seminários, cerimónias e eventos de natureza similar; o encerramento de todas as áreas de atendimento presencial a utentes 
em todas as unidades da Universidade; a suspensão da mobilidade outgoing e incoming de estudantes, professores, investigadores e trabalhadores técnicos, administrativos e de gestão. Estabelece-se que será privilegiado, sempre que possível, o teletrabalho, cabendo aos responsáveis das unidades da Universidade definir o modo de organização do trabalho.

Para os estudantes que se encontravam na Residência Carlos Lloyd Braga e na Residência de Santa Tecla (Bloco B e Bloco D) era determinado que aí se mantivessem em quarentena, sendo-lhes asseguradas as condições necessárias à sua permanência.

O quotidiano da UMinho fica em suspenso. Fica interrompido o ritmo das suas atividades. As atividades típicas da Universidade - o ensino, a investigação, a interação com a sociedade - assumem formas inabituais, os campi ficam praticamente desertos de estudantes, as atividades desportivas, culturais e recreativas são interrompidas, os regimes de trabalho alteram-se, a organização e ocupação dos espaços modificam-se profundamente, as interações entre os membros da comunidade ficam drasticamente reduzidas.

Em cerca de 48 horas, a UMinho transformara-se profundamente, passando a estar confrontada com uma das mais severas crises da sua existência.

Entretanto, na sequência da sua reunião regular do dia 10 de março, o CRUP publica um comunicado em que informa ter analisado "a evolução da situação relativa à COVID-19, bem como as indicaçóes expressas pela autoridade nacional de saúde”, entendendo que, da interação permanente com as autoridades da saúde "resulta a convicção de que até ao momento não há razões de saúde pública que justifiquem o encerramento das instalaçôes das instituições universitárias, à semelhança do que acontece com a generalidade dos setores de atividade em Portugal”.

Afirma, depois, que "irá aguardar a decisão que decorra da reunião entre o Governo e o Conselho Nacional da Saúde Pública”, agendada para o dia 11 de março. O CRUP manifestava a sua intenção de permanecer "atento ao desenrolar da situação" e compromete-se com a tomada de "todas as medidas que as autoridades de saúde considerem necessárias para a proteção da comunidade”. 
A Universidade de Coimbra havia já suspendido a atividade letiva presencial no dia 9 de março; a Universidade de Aveiro e a Universidade do Porto decidem fazê-lo no dia 11 de março, num movimento que rapidamente se estenderá à generalidade das instituiçôes de ensino superior.

\section{2 A reinvenção da Instituição - "agora estamos todos no mesmo barco"}

A suspensão do quotidiano requeria uma recriação do modo de funcionamento da Universidade, motivada pela convicção acerca da importância do seu papel, não substituível nas dimensões da promoção da educação superior, do alargamento das fronteiras do conhecimento humano e da contribuição direta para o desenvolvimento social e económico; nesta última dimensão, era convicção partilhada que a situação pandémica iria colocar grandes desafios à Instituição.

A reinvenção da Universidade, nos modos concretos da sua realização, estaria certamente muito condicionada pelas decisóes do governo do País; mas estava também ao alcance da comunidade universitária determinar aspetos importantes da vida institucional.

$\mathrm{Na}$ verdade, urgia encontrar as formas adequadas para a Universidade enfrentar a difícil situação em que se encontrava colocada. Especialmente crítica era a situação dos estudantes, com a atividade letiva suspensa.

As formas alternativas de provisão da educação começam a ser formalizadas; a circular 02/2020, publicada pela Vice-Reitora Laurinda Leite no dia 10 de março, considerando o imperativo de minimizar o impacto da suspensão de atividades letivas presenciais sobre a aprendizagem dos estudantes e sobre a organização da atividade letiva da Universidade, assume como fundamental a adoção de práticas de trabalho mediadas tecnologicamente. A circular do mesmo dia 11 de março do Pró-Reitor Manuel João Costa elenca várias possibilidades de resposta imediata, através do recurso a plataformas tecnológicas de apoio ao ensino e dá conta da disponibilização de diversos materiais formativos, incluindo sessôes acessíveis por videoconferência, bem como apoio aos docentes na gravação de aulas, na sua disponibilização online e no desenvolvimento online de atividades síncronas com os estudantes. 
As reuniôes da equipa reitoral passaram a estar largamente dominadas pelos efeitos da pandemia na Instituição.

[13 de março - Reunião da equipa reitoral. Notas pessoais]

No centro das preocupaçóes, a necessidade de retomar a atividade letiva. Relevo também para as formas de comunicação com a Universidade; importância de assegurar uma informação clara e objetiva e, por essa via, a convergência na ação institucional. Análise da organização do trabalho, com o regime de teletrabalho a ser objeto de particular atenção. A situação dos estudantes nas residências. A situação dos trabalhadores das unidades de serviços face aos trabalhadores das unidades orgânicas. A provisão de serviços de alimentação. A higienização dos espaços.

Respondendo à necessidade de assegurar a manutenção regular, embora sob novas formas, do funcionamento dos órgãos da Instituição, o despacho reitoral no 26/2020, de 13 de março, estabeleceu que, preenchidos requisitos relacionados, entre outros aspetos, com a urgência das deliberaçôes a tomar, com a sua limitação a situações que não implicassem o recurso a votação por escrutínio secreto, com o acordo dos membros dos órgãos, com a preservação dos valores e interesses subjacentes aos princípios e normas legais que impóem a participação presencial, passava a ser admitido, a título excecional, o recurso a teleconferência. Introduzia-se, assim, uma alteração relevante nas condiçôes de realização das reuniôes dos órgãos colegiais.

O dia 14 de março marcou uma opção que se veio a revelar de particular importância no desenvolvimento da resposta da Universidade à pandemia. O Conselho de Presidentes de Unidades Orgânicas passou a reunir com a participação, como convidados, dos membros da equipa reitoral e dos administradores da Universidade e dos Serviços de Ação Social, uma prática que se tornará regular nos meses subsequentes. 
[14 de março - Reunião alargada do Conselho de Presidentes de Unidades Orgânicas ${ }^{3}$. Notas pessoais]

Identificação de áreas críticas de funcionamento da UMinho no quadro pandémico, a requererem particular atenção - serviços financeiros, recursos bumanos, sistemas de informação e comunicações. Informação sobre a posição do CRUP. Condiçôes de realização das provas académicas. Migração dos trabalhadores para regime de teletrabalho; trabalhadores necessários à manutenção da atividade presencial. Avaliação da situação no desenvolvimento dos cursos; o caso dos estudantes de doutoramento e mestrado e dos respetivos projetos; implicaçôes de cenários de agravamento e das respostas possiveis ao nivel da Reitoria e das UO. Implicą̧óes da legislação recentemente aprovada (Dec.-Lei 10-A/2020). Reportado um cenário de dificuldades, com evidência da capacidade de reação das unidades orgânicas, ainda que estas tenham problemas distintos; partilham-se experiências. A informação à comunidade aparece como preocupação transversal, com particular atenção aos estudantes e à necessidade de atender, nestes, os grupos de maior risco. Impóe-se a alteração do calendário escolar; requer-se particular atenção às provas académicas; sinaliza-se a importância da fixação dos serviços minimos.

O Despacho no 2836-A/2020, de 2 de março, emitido pelos Gabinetes das Ministras da Modernização do Estado e da Administração Pública, do Trabalho, Solidariedade e Segurança Social e da Saúde tinha determinado que o plano de contingência dos empregadores públicos deveria conter procedimentos que permitissem garantir o normal funcionamento de cada serviço ou estabelecimento, privilegiando o recurso ao

\footnotetext{
3 O CPUO era integrado pelos seguintes professores: Ana Paula Macedo (Escola Superior de Enfermagem), Cristina Dias (Escola de Direito), Francisco Veiga (Escola de Economia e Gestão), Helena Machado (Instituto de Ciências Sociais), Isabel Ermida (Instituto de Letras e Ciências Humanas), Leandro Almeida (Instituto de Educação), Manuela Corte-Real (Escola de Ciências), Manuela Gomes (Instituto de Biomateriais, Biodegradáveis e Biomiméticos), Miguel Gonçalves (Escola de Psicologia), Nuno Sousa (Escola de Medicina), Pedro Arezes (Escola de Engenharia) e Pedro Bandeira (Escola de Arquitetura).
} 
mecanismo do teletrabalho, o qual só deveria ser afastado por razões imperiosas de interesse público; subsequentemente, o Decreto-Lei no 10-A/2020, de 13 de março, estabeleceu que "o regime de prestação subordinada de teletrabalho [podia] ser determinado unilateralmente pelo empregador ou requerida pelo trabalhador, sem necessidade de acordo das partes, desde que compatível com as funçóes exercidas”. Com a mesma data, a Nota Informativa - Teletrabalho, exarada pelo Gabinete do Ministro da Ciência, Tecnologia e Ensino Superior, datada de 13 de março de 2020, referia, que "as instituições de ensino superior devem fomentar e criar condiçốes para que os seus colaboradores, incluindo funcionários, docentes, investigadores e bolseiros de investigação, recorram ao teletrabalho e proceder à divulgação dessa possibilidade junto dos mesmos com vista à adoção deste regime sempre que possível, como forma de minimizar os riscos de contágio”, priorizando os grupos vulneráveis e de risco.

Estava assim criadas as condições para uma mudança significativa nas formas de organização do trabalho na Universidade, o que veio efetivamente a acontecer. A UMinho e as suas diversas unidades começam a encontrar formas de concretização do trabalho a distância, com trabalhadores em rotatividade e com implementação progressiva do teletrabalho, sem perda de eficiência.

No plano regulamentar, como forma de prevenir o risco de contágio e a proliferação da COVID-19, foi determinada na UMinho (despacho reitoral no 27/2020, de 15 de março) a possibilidade de adoção do regime de teletrabalho, entendido como prestação laboral realizada com subordinação jurídica, habitualmente fora da Universidade, através do recurso a tecnologias de informação e de comunicação, tornado possível desde que as funções exercidas fossem compatíveis com esta modalidade de trabalho e que todas as condições necessárias à sua execução se mostrassem observadas (equipamento informático, rede móvel, internet, entre outras).

Aos responsáveis das unidades é cometida a definição das tarefas a desempenhar neste regime, monitorizando o seu desenvolvimento, relativamente a cada um dos trabalhadores sob a sua direção. 
Mantinham-se, naturalmente, os mesmos direitos e deveres dos demais trabalhadores, constantes da Lei Geral do Trabalho em Funções Públicas e do Código do Trabalho. A Universidade disponibilizou aos seus trabalhadores instrumentos de trabalho, para o que contou com equipamentos das unidades orgânicas. Adicionalmente, neste mesmo despacho, era cometida aos responsáveis das unidades orgânicas e das unidades de serviços a definição de planos de contingência que deveriam prever, no caso de agravamento da pandemia, as condiçôes de realização de serviços mínimos capazes de assegurar o funcionamento básico da Unidade.

No que se foi tornando um tópico do discurso institucional, exortava-se os responsáveis das unidades a assegurar o reforço das medidas de higiene e de etiqueta respiratória nos serviços, providenciando condições e orientações para a manutenção de comportamentos de "distanciamento social".

Subsequentemente, através do despacho reitoral no 28/2020, os responsáveis das várias unidades foram instados a proceder à identificação dos trabalhadores com funções compatíveis com o regime de teletrabalho e que reunissem as condiçôes necessárias à sua execução, a proceder à identificação dos serviços essenciais que a unidade teria que assegurar em cenários de agravamento da crise sanitária e a proceder à elaboração de planos de reorganização da atividade dos trabalhadores.

Entretanto, as aulas lecionadas a distância começam a entrar em funcionamento, de forma rápida e com elevada taxa de cobertura; em alguns cursos, há reorganização dos planos estudos; o ensino clínico e os estágios são inevitavelmente afetados. Num quadro de redução geral da atividade, mantém-se alguma atividade de investigação presencial; procede-se, quando necessário e possível a reprogramação de experiências. Ganham corpo ações de formação docente.

No dia 17 de março, em mensagem escrita, dirigi-me aos membros da UMinho, reconhecendo estar o novo coronavírus a afetar gravemente a vida da Universidade. As decisões até então tomadas no sentido da restrição da atividade institucional, culminando na suspensão das atividades letivas, eram justificadas pela intenção de preservar a comunidade académica e a comunidade envolvente. Aquelas decisões estavam a ser assumidas, recordava, em estreita articulação com as autoridades de saúde, contando 
com o apoio qualificado da Comissão de Elaboração e Gestão do Plano de Contingência Interno COVID-19.

Recordei as estratégias adotadas e as ferramentas disponibilizadas para manter as atividades de ensino e aprendizagem, assinalando que, com este objetivo, tinham sido desenvolvidos e disponibilizados materiais formativos de apoio ao ensino a distância e tinha sido reforçada a capacidade de a Universidade acomodar acessos remotos; havia também sido aumentado o parque de computadores portáteis da Universidade, para servir o grande número de trabalhadores que tinha passado a desenvolver a sua atividade em teletrabalho. Lembrei também a adoção de regras de validação das decisões tomadas pelos órgãos de governo das unidades orgânicas em reuniões por teleconferência.

Destacava o facto de a Universidade vir mantendo em constante monitorização a situação dos estudantes de mobilidade in e out, valorizando o papel dos Serviços de Ação Social, que tinham adotado medidas especiais de apoio aos estudantes, designadamente às largas dezenas que se encontram em quarentena nas nossas residências universitárias.

Sinalizava, ainda, o facto de as unidades de serviços estarem a assegurar as suas funções, privilegiando o teletrabalho. Recordava, por fim, o facto de a Universidade estar a informar a comunidade através da página COVID-19 da UMinho, com orientações, informações e materiais de divulgação úteis.

Neste comunicado, apelei aos membros da comunidade para que, dentro da esfera de ação de cada um, contribuíssem ativamente para evitar a propagação da COVID-19, e agradeci aos docentes e aos investigadores, aos estudantes, aos trabalhadores técnicos, administrativos e de gestão e a todos os dirigentes pela atitude serena e posição responsável, de disponibilidade e empenho manifestados, concluindo com a expressão de confiança em que a Universidade e o nosso país saberiam, com o compromisso responsável de todos, ultrapassar o difícil momento que vivíamos. 
[18 de março - reunião alargada do Conselho de Presidentes de Unidades Orgânicas. Notas pessoais]

As alteraçôes ocorridas no plano legal e no plano regulamentar, incluindo a declaração do estado de emergência. O papel da Universidade no apoio à comunidade extrauniversitária e universitária. A página COVID-19, no site da UMinho, como fonte essencial de informação para a comunidade. As medidas de reforço da segurança e da capacidade de resposta em áreas criticas como a financeira, os recursos bumanos e os serviços académicos. A desaceleração da execução dos projetos de investigação. Implicações financeiras para a Instituição da situação que se estava a viver. $O$ apoio aos estudantes pelos Serviços de Documentação. O papel do Fundo Social de Emergência da UMinho.

A Universidade prosseguia a transição da atividade de ensino para ambientes online, com um importante número de unidades curriculares já em funcionamento regular; houve unidades orgânicas que estabeleceram como objetivo de curto prazo o funcionamento pleno das suas unidades curriculares neste ambiente. Foram-se complexificando e sofisticando as formas de uso dos dispositivos tecnológicos. Permaneceram preocupaçóes com os estágios e com o ensino clínico. Os Serviços de Documentação da Universidade operacionalizaram procedimentos para manutenção do serviço de empréstimo bibliográfico.

As questôes relativas à capacidade de resposta tecnológica da Universidade foram ganhando relevo, com a Universidade a encontrar diversas respostas ao nível da infraestrutura e também da capacitação dos docentes. Discutiam-se procedimentos de monitorização do trabalho a distância. Os órgãos da Universidade e das escolas e institutos recuperavam, em novos moldes, o seu funcionamento regular. Emergiram questôes relativas à segurança dos edifícios e das pessoas, sendo suscitada a possibilidade de distribuição de equipamentos de proteção individual. 
Coesão e compromisso afirmam-se, então, como fatores de convergência dentro da Universidade.

[20 de março - Conselho de Gestão dos Serviços de Ação social. Notas pessoais]

Análise da atividade dos Serviços no quadro pandémico - alimentação, alojamento e atividade desportiva. Apoio aos estudantes em quarentena e estudantes estrangeiros.

Os Serviços de Ação Social começam a sofrer um enorme impacto da pandemia, com toda a sua atividade fortemente afetada pela suspensão de muitas atividades na Universidade. $\mathrm{O}$ facto de a esmagadora maioria dos estudantes ter regressado a suas casas, a adoção generalizada do trabalho a distância e as próprias medidas restritivas à prestação dos serviços tradicionais dos SASUM provocam uma severíssima redução na atividade de uma estrutura que conta com mais de 250 trabalhadores.

O maior esforço estava, por esta altura, a ser colocado no apoio aos então mais de 70 estudantes que se encontravam em quarentena, bem como a estudantes estrangeiros alojados em residências da UMinho ao abrigo de quadros de colaboração internacional. No seu conjunto os serviços de ação social passam a fornecer não mais do que cerca de 400 refeições diárias.

[20 de março - Reunião da equipa reitoral. Notas pessoais]

A comunicação com a comunidade universitária como assunto central:papel do site COVID-19; a comunicação regular com a Academia e a comunicação com os estudantes; o papel de uma app UMinho; a diversificação dos canais de comunicação. As atividades de educação - a universidade a trabalhar remotamente a 100\%; a avaliação das aprendizagens como área critica; a necessidade de se retomar o serviço de empréstimo de livros; a 
importância da formação dos docentes. A alteração do projeto da Universidade com a redução da atividade cultural; planos de reorganização das atividades.

Surgem interrogações sobre a capacidade de a infraestrutura tecnológica suportar as exigências que the eram colocadas por tão elevadas taxas de utilização como as que se passaram a verificar. Dada a eficácia da reação da Universidade e a opção generalizada pelo desenvolvimento dos seus cursos mediado por recursos tecnológicos, questóes como o apoio aos estudantes, a formação dos docentes para novos desafios pedagógicos e a avaliação vão ganhando centralidade. Diagnosticada a situação como "crise dramática”, a palavra de ordem é a reinvenção da Universidade.

Através de um despacho reitoral publicado em 21 de março, procedeu-se a uma prorrogação excecional dos prazos para requerimento de provas de mestrado e doutoramento; a realização destas provas, algumas delas com data já prevista, era também um imperativo, sobretudo nos casos em que a sua concretização era condição ora para efeitos profissionais ora para regresso aos países de origem. No mesmo dia, um outro despacho fixou um regime excecional e temporário de funcionamento de júris e provas académicas, determinando a possibilidade de realização de provas públicas de mestrado e de doutoramento, bem como de provas para atribuição do título académico de agregado ou do título de especialista por videoconferência, desde que se encontrassem reunidas condiçóes de natureza tecnológica, houvesse acordo entre o júri e o candidato e a natureza pública das provas fosse garantida pela divulgação do URL de acesso à sessão de videoconferência.

[23 de março - Reunião alargada do Conselho de Presidentes de Unidades Orgânicas. Notas pessoais]

Regulamentação sobre requerimento de provas públicas de mestrado e doutoramento. Regime excecional de funcionamento de júris e provas académicas. Identificação dos serviços essenciais da Universidade; trabalho com 
funçôes compativeis com teletrabalho; elaboração de planos de reorganização da atividade dos trabalhadores. Regime de funcionamento dos edifícios, com acesso condicionado. Recolba de equipamentos de proteção individual para as instituiçôes. A avaliação das aprendizagens: elementos de avaliação; regime presencial ou a distância; orientações gerais versus orientações por UO. Avaliação em tempo de crise.

A atividade da universidade, fortemente regulada pelas disposiçóes do governo e, em particular, das autoridades da saúde encontra, no debate interno, um fator essencial para uma recontextualização adequada daquelas disposiçóes, criando-se, por esta via, condições para uma melhor resposta à crise, para a manutenção do cumprimento da essência da missão da Universidade e para melhor preparar a retoma da atividade.

Naturalmente pressentiu-se, desde cedo, impactos sérios na organização e no funcionamento da Universidade. Desde cedo, também, se percebeu que a UMinho iria dar uma resposta à altura dos desafios com que se confrontava. As prioridades estavam tornadas claras: assegurar o funcionamento da Instituição; garantir que os estudantes pudessem prosseguir a sua formação, reforçando-se para esse efeito a infraestrutura tecnológica, suprindo necessidades de equipamentos e mantendo o acesso a recursos bibliográficos; assegurar a manutenção de apoios sociais indiretos, designadamente ao nível da alimentação e das residências; manter, nas condições possíveis, as experiências de mobilidade dos estudantes; garantir a credibilidade dos processos educativos, reforçando a qualidade da avaliação das aprendizagens; apoiar as populaçóes e as entidades do SNS, na linha do aprofundamento das interaçóes da Universidade com a sociedade que é um objetivo permanente da UMinho.

[30 de março - Reunião alargada do Conselho de Presidentes de Unidades Orgânicas. Notas pessoais]

Júris e provas académicas: aspetos operacionais. Concursos da carreira docente: modos de adequação ao contexto pandémico. Orientaçôes para o 
desenvolvimento da atividade letiva ao longo do 20 semestre. Fixação do valor das propinas para o ano letivo de 2020-21. Estágios cientificos avançados.

A perceção de que a Universidade estava, apesar das dificuldades contextuais, a atuar de modo efetivo, garantindo o essencial da sua ação educativa e também a convicção de que a Universidade precisava de, num quadro de grande instabilidade, em contínua mutação, encontrar referenciais de estabilidade para os seus membros que permitissem planear e projetar a sua atividade no futuro próximo, esteve na base de uma decisão marcante: a de determinar que a atividade letiva relativa ao 20 semestre do ano letivo de 2019-20 fosse assegurada em regime de ensino a distância, devendo a avaliação das aprendizagens ser realizada em consonância com esta decisão (despacho reitoral de 31 de março).

Considerando que a Universidade tinha realizado uma transição bem-sucedida da sua oferta educativa para modalidades de ensino e aprendizagem tecnologicamente mediadas, considerando ainda que, face à evolução da pandemia, não eram previsíveis condições que permitissem retomar as atividades letivas em regime presencial, em segurança, até ao final do semestre, o despacho em apreço estabelecia os termos e condiçốes do desenvolvimento das atividades de ensino e aprendizagem e de avaliação, como requisito para um adequado planeamento das atividades letivas até ao final do semestre e para o reconhecimento das aprendizagens realizadas.

Assim, era alargado o período letivo, de forma a permitir uma gestão mais flexível do desenvolvimento das unidades curriculares; fixava-se o período da época de exames de recurso, realizados a distância ou, se as circunstâncias epidemiológicas o permitissem, presencialmente; abria-se a época de recurso, a título excecional, a todos os estudantes que dela necessitassem para obter aprovação numa dada unidade curricular.

Adicionalmente, aos docentes, em articulação com os diretores de curso e os conselhos pedagógicos, era solicitada: a adequação das estratégias de ensino e aprendizagem e de avaliação ao contexto de ensino a distância, em todas as unidades curriculares; a disponibilização de recursos educativos que permitissem aos estudantes realizar 
atividades de aprendizagem em horários diversificados; a partilha com os estudantes das alterações introduzidas no ensino e na avaliação; o fornecimento regular de informação aos estudantes sobre a evolução das suas aprendizagens.

O mês de março é, pois, particularmente denso (e tenso) na definição de um conjunto de orientaçôes e na assunção de um conjunto de opções que largamente reconfiguraram a atividade da UMinho: nos processos académicos, nos processos administrativos, nas relações laborais e, sobretudo, na dimensão, essencial, da educação.

Neste particular, a Universidade desencadeou um importante conjunto de iniciativas que se vieram a revelar decisivas: um forte envolvimento dos docentes na migração da sua atividade para ambientes online; uma efetiva participação dos estudantes nestas atividades; um vasto número de iniciativas, regularmente desenvolvidas, de formação de docentes e de partilha de experiências, em determinado momento alargado a estudantes; a disponibilização aos estudantes de ferramentas de suporte à atividade letiva a distância.

A aposta no ensino mediado por meios tecnológicos requeria dos estudantes a existência de um conjunto de meios que aqueles nem sempre tinham disponíveis. A consciência deste facto levou a Universidade a lançar, em 9 de abril, um programa de Apoio Informático aos Estudantes - PAIE, gerido pelos Serviços de Ação Social, tendo presente que os recursos tecnológicos informáticos eram determinantes para o acompanhamento pelos estudantes das atividades de ensino e avaliação e para o seu sucesso académico. O PAIE apoiou os estudantes da UMinho em condições de carência económica através do empréstimo de curta duração de computadores, diapositivos audiovisuais e/ou serviço de internet móvel para o acompanhamento das atividades letivas em regime de ensino a distância. $\mathrm{O}$ acesso ao programa foi fortemente simplificado e os estudantes apenas tiveram que declarar encontrar-se impossibilitados de adquirir computador, dispositivos audiovisuais e/ou serviço de internet, ao abrigo do princípio da confiança mútua, mediante declaração de compromisso de honra.

Este programa contou com o apoio inestimável da rede de alumni da Universidade, através da qual foi possível garantir a doação ou a cedência de todos os computadores que se revelaram necessários. 
Com o aproximar do final do semestre letivo, o debate sobre a avaliação das aprendizagens tornou-se central. A melhoria, ainda que relativa, da situação pandémica levou o Gabinete do Ministro da Ciência, Tecnologia e Ensino Superior a emitir uma Recomendação e Esclarecimento às instituições científicas e de ensino superior, datada de 17 de abril, no sentido de serem elaborados planos para o levantamento progressivo das medidas de contenção motivadas pela pandemia COVID-19, nos vários domínios de atuação das Universidades. Esta recomendação previa o estabelecimento de medidas que estimulassem a continuação da adoção de processos de ensino e aprendizagem a distância e de teletrabalho, promovendo, sempre que possível, a sua combinação gradual e efetiva com atividades presenciais, designadamente destinadas a aulas práticas, aulas laboratoriais e avaliação final, garantindo-se o cumprimento das recomendações das autoridades de saúde competentes e as normas técnicas em vigor.

O despacho reitoral no 33/2020, de 30 de março, havia previsto que a atividade letiva relativa ao 2o semestre do ano letivo de 2019-2020 seria assegurada em regime de ensino a distância, devendo a avaliação das aprendizagens ser realizada em consonância com tal decisão.

[20 de abril - Reunião alargada do Conselho de Presidentes de Unidades Orgânicas. Notas pessoais]

Análise da aplicação do despacho RT-33/2020: as especificidades das unidades curriculares laboratoriais e com componente performativa; o caso dos estágios em empresa. Novas formas de acompanhamento do trabalho dos estudantes. Orientações a adotar na avaliação das aprendizagens; possibilidades e condiçôes da avaliação presencial e da avaliação a distância. A retoma da atividade de investigação.

Entretanto, a Comissão de Elaboração e Gestão do Plano de Contingência Interno COVID-19 da Universidade do Minho divulgou, em 27 de abril, recomendações em que aconselhava a manutenção do regime de ensino e avaliação a distância até ao final do 2o semestre de 2019-2020, com adoção de procedimentos de avaliação 
presencial de aprendizagens, na época normal, apenas nas unidades curriculares em que as funcionalidades das plataformas tecnológicas não fossem de todo adequadas às especificidades da unidade curricular ou quando as necessidades específicas dos alunos o exigissem.

Neste quadro, a que se deve acrescentar as "Orientaçốes para utilização de tecnologias de suporte ao ensino à distância” emitidas pela Comissão Nacional de Proteção de Dados (CNPD), em 8 de abril de 2020, visando garantir que a utilização das plataformas para ensino a distância seguisse as boas práticas respeitantes à proteção de dados, a Universidade fixou orientações para a avaliação dos estudantes.

Através de um despacho reitoral datado de 3 de maio, relativo a orientações para o ensino e a avaliação no contexto da COVID-19, foi determinado que a Universidade manteria o ensino e a aprendizagem a distância até ao final do 2o semestre, identificando-se posteriormente as unidades curriculares para as quais, verificadas condiçóes sanitárias adequadas, deveria ser equacionada a realização presencial de atividades laboratoriais, artísticas ou de campo; determinava-se, ainda, que a avaliação das aprendizagens seria realizada preferencialmente a distância; nos casos de inadequação deste regime de avaliação, as provas seriam realizadas presencialmente, garantidas que ficassem as condições sanitárias adequadas. Aos estudantes que, no decorrer da situação pandémica, tivessem regressado ao seu local de residência ou país de origem, estando impedidos de participar em atividades letivas e de avaliação presenciais, estas ser-lhes-iam providenciadas a distância.

A fixação de orientaçốes para a avaliação assentava num pressuposto - o da grande relevância dos resultados da avaliação para o percurso académico e pós-universitário dos estudantes, bem como para o reconhecimento social das aprendizagens realizadas.

Entendia-se que era obrigação da Universidade assegurar que as circunstâncias extraordinárias que se viviam não deviam implicar prejuízos adicionais para os estudantes, minimizando-se, pois, os impactos dessas circunstâncias sobre os seus percursos académicos. 
Por outro lado, à Universidade caberia garantir credibilidade e legitimidade aos processos de ensino e aprendizagem desenvolvidos e assegurar que a avaliação das aprendizagens obedecesse ao princípio da transparência. Focando o papel dos estudantes, o documento estabelecia que:

- a avaliação devia reforçar o compromisso dos estudantes com as atividades letivas e com o processo de aprendizagem;

- a Universidade devia permitir que os estudantes pudessem ser atempadamente avaliados em todas as unidades curriculares em funcionamento;

- a Universidade devia assegurar o acesso de todos os estudantes ao processo de avaliação, em condições de igualdade, mas atendendo à diversidade das suas necessidades;

- a Universidade devia evitar a sobrecarga dos estudantes provocada pela multiplicidade de momentos e instrumentos de avaliação;

- a Universidade devia corresponsabilizar os estudantes pela integridade do processo de avaliação das aprendizagens; e, ainda,

- a avaliação devia gerar resultados capazes de discriminar diferentes compromissos e diferentes níveis de aprendizagem.

Estas orientações eram depois corporizadas num conjunto de medidas que as especificavam e que balizavam, com flexibilidade, as práticas de avaliação a seguir, assim se dando confiança num processo particularmente desafiante

Na sequência da cessação do estado de emergência e da declaração da situação de calamidade em todo o território nacional, aprovadas pelo Conselho de Ministros em 30 de abril, e consequente estratégia de levantamento de medidas de confinamento, impôs-se a adoção de um conjunto de orientaçóes que visavam assegurar que tal ocorresse de modo progressivo e eficaz. 
[4 de maio - Reunião alargada do Conselho de Presidentes de Unidades Orgânicas. Notas pessoais] Apreciação de orientaçôes para o levantamento progressivo das medidas de contenção; importância de soluçôes flexiveis. Condições de desenvolvimento da atividade educativa nas unidades orgânicas. A avaliação das aprendizagens: limitaçôes à sua realização presencial; procedimentos a adotar para a sua concretização.

Subsequentemente, o despacho reitoral no 45/2020, de 8 de maio, determinou orientações e medidas a adotar em todas as unidades da Universidade, entre as quais:

- o incremento das atividades de investigação e inovação desenvolvidas nos laboratórios e outros espaços da Universidade, inclusive no âmbito de dissertaçôes de mestrado e teses de doutoramento;

- a intensificação do funcionamento de serviços de apoio à comunidade académica, designadamente nas áreas das bibliotecas, da alimentação, do alojamento e do desporto;

- a manutenção do regime de teletrabalho, sempre que as funções dos trabalhadores o permitissem, promovendo a sua combinação gradual e efetiva com atividades presenciais, com especial proteção das pessoas de grupos vulneráveis e de risco;

- a retoma do atendimento presencial nas diversas unidades da Universidade;

- a criação de condições de segurança adequadas nos locais de trabalho, com cumprimento rigoroso das recomendaçóes das autoridades de saúde competentes e da tutela.

[8 de junho - Reunião alargada do Conselho de Presidentes de Unidades Orgânicas. Notas pessoais]

Reflexão sobre a situação atual da Universidade: uma situação excecional; 
a convergência em torno de objetivos institucionais; a percę̧ão pública do papel das universidades; a crise, o orçamento retificativo e o Programa de Estabilização Económica e Social; a coesão institucional como necessidade. Preparação do ano letivo: princípios e orientaçóes. Regulamento da carreira, recrutamento, contratação e avaliação do desempenho do pessoal investigador.

A Resolução do Conselho de Ministros de 29 de maio, depois alterada e republicada por Resolução do mesmo Conselho de Ministros de 12 de junho, prorrogou a declaração da situação de calamidade, dando continuidade ao processo de desconfinamento, com menos constrangimentos do que aqueles até então vigentes.

Neste quadro, o despacho reitoral no 52 de 15 de junho, revogou muitas das disposiçóes que haviam configurado a atividade da Universidade nos meses anteriores, mantendo-se embora restrições relativas, por exemplo, à observância das regras de ocupação dos espaços, permanência e distanciamento físico, bem como às regras de higiene determinadas pelas autoridades de saúde e pela legislação em vigor, em todas as atividades da Universidade; mantinham-se genericamente em vigor medidas excecionais e temporárias relativas a júris de concursos e provas académicas, bem como o atendimento presencial por marcação prévia pelas unidades da Universidade, e ainda a prestação dos serviços através de meios digitais. Posteriormente, foram fixadas novas orientaçóes e procedimentos a observar em matéria de teletrabalho e organização de trabalho que reviam procedimentos de exceção até então em vigor.

No plano normativo, o despacho reitoral no 5, de 26 de junho, que procedeu ao planeamento do ano letivo de 2020/21, abriu um novo ciclo no funcionamento da Universidade.

Aí se assume, entre outros aspetos, que o conhecimento científico disponível sugeria que a infeção pelo novo coronavírus só deixaria de ser preocupante depois de haver uma vacina eficaz contra a COVID-19 ou de se atingir um bom nível de imunidade comunitária e que, até lá, poderiam vir a ocorrer novas vagas da doença; que as 
recomendações das autoridades de saúde competentes, nomeadamente ao nível sanitário, de etiqueta respiratória e de higiene, e do distanciamento físico impunham a redução da capacidade útil das salas de aula e de outros espaços pedagógicos; que a educação superior, tal como é assumida pela UMinho, tinha nas atividades letivas presenciais uma componente essencial, que só circunstâncias excecionais justificavam ver alterada; que se tornava necessário assegurar referentes estáveis para todos os envolvidos no processo educativo, que permitissem uma planificação atempada e adequada das atividades letivas para o ano escolar subsequente; que a autonomia pedagógica e científica das unidades orgânicas lhes permitiria identificar as melhores formas de organizar as atividades letivas, de modo a maximizar a qualidade pedagógica da formação oferecida e o funcionamento regular dos cursos ao longo do ano.

Nestas circunstâncias, era fixado para o planeamento do ano letivo 2020/2021 um conjunto de orientaçốes, em que sobressaíam as seguintes:

- os cursos deveriam contemplar atividades letivas presenciais e não presenciais, tendo em consideração as restrições de espaço impostas pelas determinações das autoridades de saúde, sendo o peso relativo das componentes presencial e não presencial dos cursos fixado pelas unidades orgânicas;

- as atividades letivas de natureza laboratorial, artística ou de campo deveriam ter realização presencial;

- o regime presencial deveria ser privilegiado no 1o ano das licenciaturas e mestrados integrados;

- as atividades pedagógicas e de investigação prevaleceriam sobre as restantes na utilização dos espaços da Universidade.

Quanto à infraestrutura tecnológica de suporte às atividades de ensino e avaliação, ficou estabelecido que a Universidade providenciaria espaços, equipamentos e apoio técnico para a produção de conteúdos multimédia; que a Universidade garantiria o acesso a plataformas de avaliação das aprendizagens; e, por fim, que a Universidade disponibilizaria apoio tecnológico a estudantes carenciados. 
Quanto ao acolhimento dos novos estudantes, a matrícula dos estudantes do 1o ano, tal como as dos restantes anos, seria efetuada online, assim como a candidatura a alojamento nas residências.

O despacho atribuía aos órgãos competentes das unidades orgânicas a responsabilidade da adoção dos procedimentos necessários à preparação do ano letivo seguinte, designadamente em relação à elaboração dos horários, considerando para o efeito os espaços pedagógicos da Universidade afetados aos cursos cuja gestão lhes cabe.

Num ambiente ainda de crise, que se antecipava poder continuar a ser, com grande probabilidade, aquele em que iria decorrer o novo ano letivo, decisóes estruturantes relativas à atividade da Universidade, eram tomadas como forma de garantir horizontes de estabilidade para o funcionamento da Universidade.

\section{Os dias por vir: o contágio é um convite a que [nos] pensemos}

Este texto é finalizado no momento em que vivemos a chamada "segunda vaga" da COVID-19, facto este que permite condições adicionais de reflexão não só sobre os impactos globais e locais da crise na UMinho, mas também sobre a natureza da reação que a Universidade protagonizou, nas suas condiçôes, princípios e efeitos, possibilitando, ainda, projeçôes sobre os caminhos que se oferecem à Instituição.

Da capacidade de a UMinho, enquanto Instituição, se pensar a si própria e às suas circunstâncias, dá esta obra testemunho. Uma Universidade plural, multidisciplinar, aberta aos seus contextos, motivada por uma circunstância difícil, disponibiliza, através dos seus membros, leituras da crise pandémica ou a propósito dela, que materializam uma dimensão essencial da Universidade: alargar o conhecimento humano e partilhá-lo, possibilitando um entendimento mais acurado de nós próprios e das nossas circunstâncias.

A UMinho reagiu de forma madura à crise com que foi confrontada. Ainda que os resultados dessa reação tivessem sido outros, diferentes dos desejados, ter-se-iam retirado ensinamentos particularmente importantes sobre o modo como a Universidade deve atuar em circunstâncias tão inesperadas como as que vivemos. A Universidade 
não é, não pode ser, lugar de pensamento único ou espaço em que se presume não haver alternativas. Elas existem sempre. Ainda assim, foi possível criar as convergências necessárias, em cada momento, para que a Universidade pudesse prosseguir a concretização da sua missão. Como foi também possível, dentro da imprevisibilidade que marcou todos os dias, encontrar espaço para a ação planeada, capaz de gerar o reconhecimento de que havia um rumo, de que era possível, dentro da tormenta, antecipar pontos de chegada. As decisóes, cedo tomadas, após o necessário debate, de manter a atividade letiva tecnologicamente mediada até ao final do ano letivo de 2019-2020, de realizar, nesse ano, a avaliação das aprendizagens à distância, de fixar o funcionamento do ano letivo de 20-21 em regime misto, permitiram criar um ambiente de normalidade e de previsibilidade, que foi fundamental para que não ficasse suspensa a concretização de objetivos essenciais da Universidade na área da educação.

A decisão partilhada e a comunicação têm-se revelado fatores essenciais de indução de regularidade no funcionamento da Universidade. Em poucos momentos da vida da Instituição terão sido tão frequentes as reuniôes (e já agora tão demoradas) dos órgãos da Universidade, terão sido tão recorrentes os comunicados à academia, terá sido tão sistemática a difusão, por todos os canais, de informação sobre o funcionamento da Universidade. Um dos resultados pretendidos com esta opção era o de que decisão colegial e a informação partilhada fossem fatores de confiança acrescida na Instituição e na sua capacidade de enfrentar as dificuldades com que se confrontava.

A reação da Universidade ultrapassou, porém, em muito, o que se podia esperar do mero cumprimento das decisóes institucionais. A rapidez e a qualidade da migração da oferta educativa para ambientes online, o envolvimento ativo de docentes e estudantes em novos ambientes pedagógicos, a disponibilidade para aprender novos modos de ensinar e aprender, a manutenção do essencial da atividade de investigação, a continuação do funcionamento, em novos moldes, embora, dos serviços de apoio deve-se ao ânimo renovado e ao compromisso da comunidade universitária, a quem se se deve também o extraordinário apoio que foi dado às entidades do Sistema Nacional de Saúde e às nossas populações através da ação de muitos investigadores e centros de investigação, das escolas e dos institutos, bem como de estruturas especializadas da Universidade como a Associação de Psicologia ou o Centro de Medicina Digital P5; a 
interação com a sociedade ganhou, em tempos de pandemia novas e muito significativas formas de concretização.

A reinvenção de si mesma que a Universidade protagonizou deve-se, de forma insofismável, aos docentes e investigadores, aos estudantes, aos trabalhadores técnicos, administrativos e de gestão. Certamente nem tudo correu como era desejado, erros terão sido cometidos, mas globalmente a Universidade pode, e deve, orgulhar-se do que realizou.

E agora?

A experiência acumulada ao longo dos últimos meses teve indiscutível impacto sobre o modo como a comunidade académica passou a pensar a Universidade e a nela atuar. Consolidaram-se tendências emergentes que podem vir a configurar alterações importantes nas formas de concretizar o mandato das instituiçóes de ensino superior, na esteira do que se observa em outros contextos nacionais. A transição digital em curso vai afetar, com certeza mais depressa do que imaginaríamos há um ano, os modos de funcionamento das universidades. $\mathrm{O}$ debate em torno do papel da educação não presencial na educação superior é um bom exemplo das tensões que hoje atravessam o campo do ensino superior, com uma intensidade a que a crise pandémica não é indiferente. A este respeito, a posição da UMinho é, porém, clara; o seu projeto educativo, na sua génese e no seu desenvolvimento, sempre assumiu a interação pessoal, em presença, como indissociável da ação pedagógica; da educação superior sempre tivemos o entendimento de que, nos seus objetivos e no seu âmbito, ela requer experiências que só a vivência dos campi universitários pode assegurar. Não se trata de recusar inevitáveis mudanças decorrentes das transformações tecnológicas em curso, mas antes de continuar a pensar a essência da educação universitária. 